\title{
Comparison between preoperative computed tomography scan of paranasal sinuses and operative findings in functional endoscopic sinus surgery (FESS) in chronic sinusitis
}

\author{
Kumari A ${ }^{1}$, Kaur A. ${ }^{2}$, Mathur M. ${ }^{3}$, Singh J. ${ }^{4}$, Mohi J.K. ${ }^{5}$, Haq S $^{6}$ \\ ${ }^{1}$ Dr. Amita Kumari, Senior Resident, ${ }^{2}$ Dr. Amarjit Kaur, Professor, ${ }^{3}$ Dr. Manoj Mathur, Associate Professor, ${ }^{4}$ Dr. Jasvir \\ Singh, Junior, Resident, ${ }^{5}$ Dr. Jaswinder Kaur Mohi, Associate Professor, ${ }^{6}$ Dr. Samrin Haq Junior Resident, all authors are \\ attached with department of Radiology, GMC, Patiala, Punjab, India
}

Address for correspondence: Dr. Jasvir Singh, Email: jasvirsingh011789@gmail.com

\begin{abstract}
Background and objectives: The study was done to evaluate the role of computed tomography (CT) in clinically suspected cases of chronic sinusitis for detection, assessment of anatomical variants and pathological abnormalities of nasal cavity and paranasal sinuses. Also findings of CT were co-related with operative findings in functional endoscopic sinus surgery (FESS). The study was conducted on 60 cases attending CT section of Radiodiagnosis Department and ENT Department Rajindra Hospital, Patiala. Materials and Methods: The study was conducted on 60 cases over a period 3 years from 2010 to 2013 irrespective of gender and age group attending the ENT and radiology department. Selections of patients were based on clinical features like nasal or post nasal discharge, nasal obstruction, headache anosmia, cough and hoarseness of voice. Relevant history, clinical examination and CT examination of every patient were done. Results: In our study, the CT scan and operative findings correlated excellently in cases of paradoxical middle turbinate, bony destruction, concha bullosa, polypoidal changes in ethmoidal sinuses and osteomeatal complex normal widening. There was very good agreement between preoperative CT scan and operative findings for concha bullosa, paradoxical middle turbinate, bony destruction, osteomeatal complex normal widening, polypoidal change in sphenoid sinus. The most common pattern observed on CT scan was osteomeatal unit pattern in 35\% followed by infundibular pattern (20\%), sphenoethmoidal recess pattern (23.3\%), unclassified pattern (15\%) \& sinonasal polyposis pattern $(6.6 \%)$. Conclusion: CT is the imaging modality of choice to reveal mucosal changes deeper in osteomeatal complex which are not visible endoscopically and to identify extent of paranasal sinus disease. However, endoscopy has complementary role with CT in evaluation of patients of chronic sinusitis.
\end{abstract}

Keywords: Chronic sinusitis, Computed Tomography, FESS.

\section{Introduction}

The term sinusitis refers to a group of disorders characterized by inflammation of mucosa of paranasal sinuses. Rhinosinusitis is replacing the term sinusitis because sinusitis is often preceded by rhinitis and rarely occurs without concurrent nasal airway inflammation $[1,2]$. The article "Adult Rhinosinusitis Defined" characterizes rhinosinusitis into 5 separate clinical categories: acute, subacute, chronic, recurrent acute and acute exacerbation of CRS. Acute rhinosinusitis is a

Manuscript received; $04^{\text {th }}$ December 2016

Reviewed: $12^{\text {th }}$ December 2016

Author Corrected: $20^{\text {th }}$ December 2016

Accepted for Publication: $30^{\text {th }}$ December 2016 clinical condition lasting less than 4 weeks, and subacute rhinosinusitis is present for more than 4 weeks but less than 12 weeks [1]. Chronic sinusitis is a clinical diagnosis and is defined as a rhinosinusitis lasting $>12$ weeks that includes two or more major sinus symptoms or at least one major and two minor sinus symptoms with or without findings on physical examination[1].

Chronic sinusitis is diagnosed when the patient has repeated bouts of acute infection or persistent inflammation. Staphylococcus, streptococcus, corynebacteria, bacteroides, fusobacteria, and other 
anerobes are more commonly involved in chronic sinusitis than in acute sinusitis[3]. The sinuses most commonly involved with chronic sinusitis are the anterior ethmoid air cells.

Plain radiography has limited value for imaging paranasal sinuses, especially the ethmoid sinuses and the ostiomeatal complex and its use is not indicated[4,5].

Computed tomography is the imaging method of choice for the paranasal sinuses. CT is the imaging study of choice in both adult and pediatric patients[6]. CT is the technique of choice in the preoperative evaluation of the nose and paranasal sinuses and is the gold standard for delineation of inflammatory sinus disease resulting from obstruction[7].

The two primary diagnostic imaging techniques for evaluating the paranasal sinuses are CT and MRI. Radiography was once the most commonly ordered study; however, CT has surpassed radiography in the evaluation process because of its superior anatomic detail and when a lower $\mathrm{mA}$ protocol is used, a radiation dose similar to a standard four-view radiographic series[8,9].

The use of a bone algorithm provides excellent resolution of the complete osteomeatal complex and other anatomic factors that play a role in sinusitis. Coronal CT images most closely correlate with the surgical approach[9].

Therefore, it is the preferred study for the surgeon performing functional endoscopic sinus surgery (FESS) because coronal images simulate the appearance of the sinonasal cavity from the perspective of the endoscope[10].

The characteristic findings of sinus disease include airfluid levels, mucosal thickening, and opacification of the normally aerated sinus lumen. The single distinguishing feature of acute sinusitis is the air-fluid level as an isolated finding, whereas the only characteristic finding in chronic sinusitis is sclerotic, thickened bone of the sinus wall[11].

It is critical to identify the technique of choice for preoperative screening and evaluation. CT is superior to MRI for the delineation of the fine bone structures of the infundibular complex, orbital lamina, orbital floor, and cribriform lamina [12]. Thus, CT is superior to MRI in planning FESS[13]. With MRI, these bone structures have low signal intensity, making them difficult to completely assess.

CT was also used to evaluate following anatomical variations:

- Variations of the middle nasal concha

- Concha bullosa

- Middle paradoxical concha

- Uncinate process variations

- Ethmoid variations

- Haller air cells

- Giant ethmoid bulla

- Agger nasi cells

- Hyperpneumatrization of the sphenoidal sinus

- Medial protrusion of the lamina papyracea

- Nasal septal deviation.

\section{Material and methods}

The present study was a hospital based prospective study conducted in Rajindra Hospital Patiala in patients who presented with clinical symptoms of chronic sinusitis. The study sample was limited to 60 patients and was done over a period of three years from 20102013. Institutional review board approval for conducting this study was obtained and informed consent of study patients was taken.

CT scan was performed with Siemens- Somatom Emotion 6 slice third generation spiral CT. Slices of 5 $\mathrm{mm}$ were taken in axial and coronal planes. The coronal plane depicts anatomy in a way somewhat similar to what ENT surgeon will see as the nasal vault is approached with an endoscope. It is also the imaging plane which best displays the osteomeatal unit. Coronal scan was done with patient lying prone with chin hyperextended and gantry tilted to the approximate plane at right angle to the orbitomeatal line.

Scanning was done from anterior wall of frontal sinus to posterior wall of sphenoid sinus. In all the patients functional endoscopic sinus surgery was done under local anaesthesia 2\% lignocaine with 1:1,00,000 adrenaline was used for mucosal infiltration for anaesthesia and vasoconstriction.

Patients were placed in supine position with head turned towards examiner. Endoscope was fixed just above the nostril with thumb and forefinger of left hand while it was gently introduced with right hand, care was taken not to cause mucosal damage. Endoscope was 
introduced initially along the floor of nose till nasopharynx was seen and then withdrawn slowly to look for disease pathology. It was then removed and reintroduced below the middle turbinate to examine middle meatus and sphenoethmoidal recess. When endoscope was in middle meatus, the uncinate process, bulla ethmoidalis, hiatus semilunaris, infundibullar opening and maxillary sinus opening were inspected. The endoscope was passed posteriorly after viewing the middle meatus area to examine sphenoethmoidal area. Depending upon disease appropriate endoscopic sinus surgery was done which could be uncinectomy, middle meatus antrostomy, anterior ethmoidectomy, posterior ethmoidectomy, sphenodotomy, resection of middle turbinate.

Statistical Analysis: The data was statistically analysed and was compared by using kappa value.

\section{Results}

The present study was conducted in the departments of Radiodiagnosis and ENT, Rajindera Hospital, Patiala on 60 patients, clinically diagnosed to have chronic sinusitis. The findings of the CT scan were correlated with operative findings of Functional Endoscopic Sinus Surgery.

In the present study, there were 35 males and 25 females in the study group. The youngest patient was 12 years old and oldest 60 years. The disease frequency was found to be maximum in age group 21-30 years (31.66\%).

The common presenting symptoms were nasal obstruction in $70 \%$ cases, headache in $66.6 \%$, nasal discharge in $65 \%$, epistaxis in $30 \%$ and post nasal drip in $20 \%$ of cases. On anterior rhinoscopy examination, deviated nasal septum (46.6\%) was the most common sign followed by inferior turbinate hypertrophy (31.6\%).

Maxillary sinus was most frequently involved in $80 \%$ cases followed by anterior ethmoid, posterior ethmoid, sphenoid \& frontal sinuses respectively.

Table-1: Mucosal abnormality of sinuses in patients of chronic sinusitis on CT scan

\begin{tabular}{|l|l|l|l|l|l|l|}
\hline \multirow{2}{*}{ Involved Sinuses } & \multicolumn{2}{|l|}{ No. of patients with involved sinuses } & \multirow{2}{*}{ Total } & $\begin{array}{l}\text { Total no. of } \\
\text { Sinuses involved }\end{array}$ & $\begin{array}{l}\text { Involved sinuses } \\
(\boldsymbol{\%})\end{array}$ \\
\cline { 2 - 6 } & Left & Right & B/L & & 96 & 80 \\
\hline Maxillary & 13 & 11 & 13 & 60 & 96 & 45 \\
\hline Anterior ethmoid & 16 & 12 & 14 & 28 & 42 & 35 \\
\hline Posterior ethmoid & 6 & 8 & & & 17 & 28.3 \\
\hline Sphenoid & & & 3 & 12 & 15 & 12.5 \\
\hline Frontal & 4 & 5 & 13 & 54 & \\
\hline
\end{tabular}

Overall $80 \%$ of maxillary (Figure 1,3), $45 \%$ of anterior ethmoid, 35\% of posterior ethmoid, $28.3 \%$ of sphenoid and $12.5 \%$ of frontal sinuses were found to have mucosal abnormality on CT scan.

Table-2: Patients of inflammatory sinonasal disease on CT scan

\begin{tabular}{|l|l|l|}
\hline Patterns & No. of Patients & Percentage \\
\hline Infundibular pattern (INF) & 12 & 20 \\
\hline Osteomeatal unit pattern (OMU) & 21 & 35 \\
\hline Sphenoethmodial recess pattern (SER) & 14 & 23.3 \\
\hline Sinonasal polyposis pattern (SNP) & 4 & 6.6 \\
\hline Unclassified pattern (UNC) & 9 & 15 \\
\hline
\end{tabular}

The most common pattern to be observed was osteomeatal unit pattern in $35 \%$, followed by sphenoethmoidal recess pattern in $23.3 \%$ of cases. Infundibular, unclassified and sinonasal polyposis pattern were observed in $20 \%, 15 \%, 6.6 \%$ of cases respectively.

DNS, Concha bullosa (Figure 2), Haller cells and onodi cells were the common anatomic variants noted in $46.6 \%$, $33.3 \%, 25 \%$ and $28.3 \%$ cases respectively. The other less common variants noted were Pneumatization of pterygoid 
process, Agger nasi cells, Pneumatization of anterior clinoid process, Enlarged bulla ethmoidalis, Paradoxical middle turbinate and Pneumatization of crista gall.

Table-3: Anatomical variations on ct scan in patients of chronic sinusitis

\begin{tabular}{|l|l|l|}
\hline Anatomical Variants & No. of cases & \%age \\
\hline Deviated nasal septum & 28 & 46.6 \\
\hline Agger Nasi cells & 10 & 16.6 \\
\hline Haller cells & 15 & 25 \\
\hline Concha bullosa & 20 & 33.3 \\
\hline Pneumatization of crista galli (PCG) & 5 & 8.3 \\
\hline Pneumatization of anterior clinoid process (PAC) & 4 & 6.6 \\
\hline Onodi cells & 17 & 28.3 \\
\hline Paradoxical middle turbinate(PMT) & 5 & 8.3 \\
\hline Pneumatization of pterygoid process (PTG) & 8 & 13.3 \\
\hline Enlarged bulla ethmoidalis & 6 & 10 \\
\hline
\end{tabular}

Table-4: Kappa agreement between preoperative CT and FESS findings in chronic rhinosinusitis $(\mathrm{n}=60)$

\begin{tabular}{|c|c|c|c|c|c|}
\hline \multirow[b]{2}{*}{ Findings } & \multicolumn{4}{|c|}{$\begin{array}{ll}\text { FESS positive } & \text { FESS negative }\end{array}$} & \multirow{2}{*}{$\begin{array}{l}\text { Kappa } \\
\text { value }\end{array}$} \\
\hline & $\begin{array}{l}\text { CT scan } \\
\text { positive }\end{array}$ & $\begin{array}{l}\text { CT scan } \\
\text { negative }\end{array}$ & $\begin{array}{l}\text { CT scan } \\
\text { positive }\end{array}$ & $\begin{array}{l}\text { CT scan } \\
\text { negative }\end{array}$ & \\
\hline DNS (Deviated nasal septum) & 28 & 2 & 1 & 29 & 0.9 \\
\hline Polyp & 11 & 3 & 5 & 41 & 0.64 \\
\hline $\begin{array}{l}\text { Mucosal thickness ( >3mm) } \\
\text { in sinuses }\end{array}$ & 38 & 0 & 6 & 16 & 0.77 \\
\hline $\begin{array}{l}\text { Right osteomeatal complex } \\
\text { blockage }\end{array}$ & 30 & 1 & 3 & 26 & 0.86 \\
\hline $\begin{array}{l}\text { Left osteomeatal complex } \\
\text { blockage }\end{array}$ & 32 & 2 & 4 & 22 & 0.8 \\
\hline $\begin{array}{l}\text { Hypertrophy of inferior } \\
\text { turbinates Anatomical variants }\end{array}$ & 18 & 1 & 2 & 39 & 0.886 \\
\hline a) $\quad$ Haller cell & 12 & 0 & 3 & 45 & 0.857 \\
\hline Onodi cell & 15 & 1 & 1 & 43 & 0.91 \\
\hline Agger nasi cell & 8 & 0 & 2 & 50 & 0.87 \\
\hline Bulla ethomoidalis & 4 & 0 & 2 & 54 & 0.78 \\
\hline Concha bullosa & 15 & 0 & 5 & 40 & 0.8 \\
\hline
\end{tabular}

(Kappa value if 0.61-0.80 then good agreement and if 0.81-1.00 almost perfect or very good agreement) 
The incidence of abnormal findings on CT was compared with FESS in table 4. There is good to very good agreement between the two diagnostic procedures as mentioned. DNS, polyp, inferior turbinate hypertrophy, mucosal thickness, osteomeatal complex blockage and anatomical variants all show kappa value $>0.6$ and CT has better detection rate in certain aspects as compared to FESS as shown in table 4.
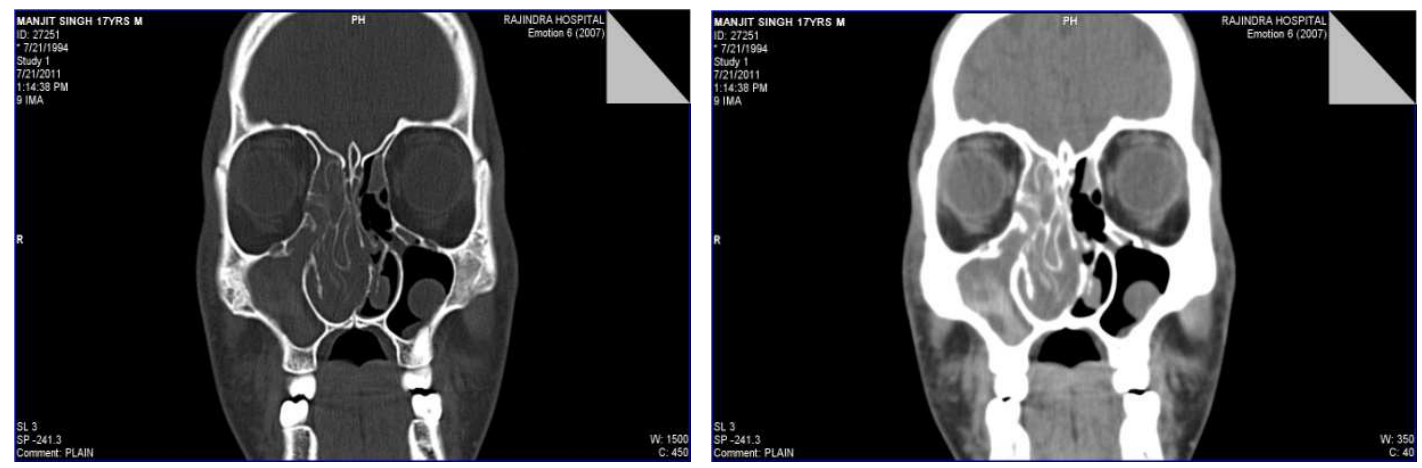

Figure-1: Coronal CT images show soft tissue density material with hyperdense foci in right ethmoidal air cells and maxillary sinus suggestive of fungal sinusitis and left maxillary polyp.
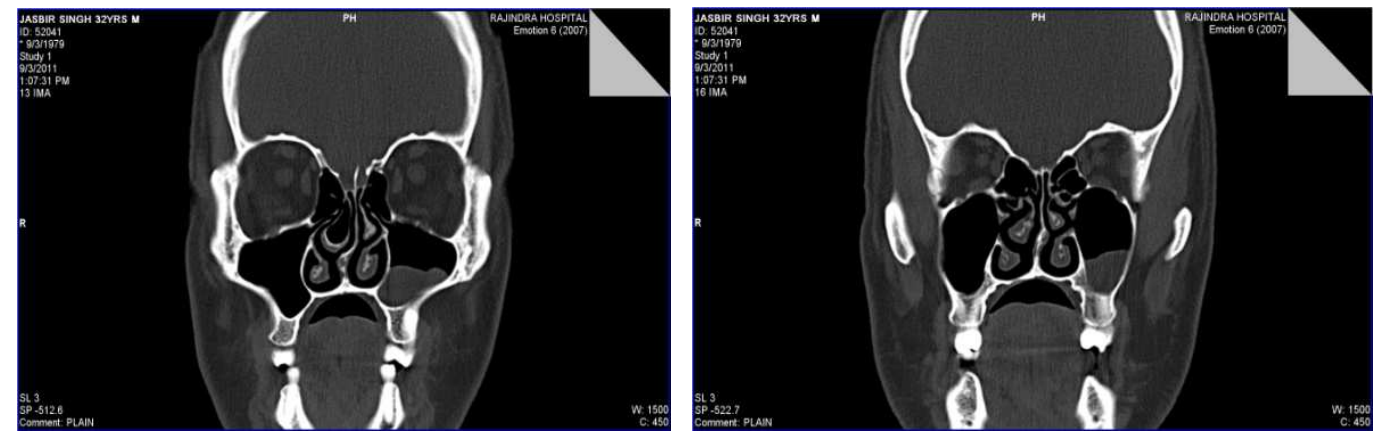

Figure-2: Coronal CT images show right sided concha bullosa with S-shaped deviated nasal septum (DNS) and left maxillary sinusitis
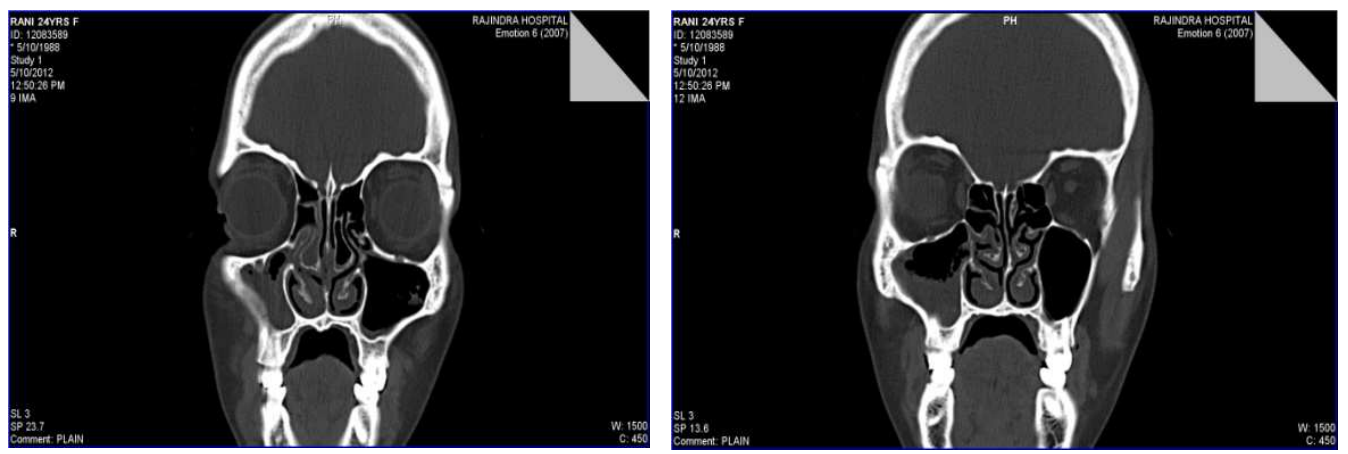

Figure-3: Coronal CT images show right maxillary sinusitis with bilateral inferior turbinate hypertrophy

\section{Discussion}

The complex regional anatomy of the paranasal sinuses has only recently been elucidated through the use of modern imaging techniques. The advent of computerized tomography in the delineation of sinonasal pathology and anatomic variations has proven invaluable to the otolaryngologist in preoperative planning for functional endoscopic sinus, surgery [14]. CT scan assessment of chronic rhino sinusitis is a reliable test. The CT findings in patients with chronic rhinosinusitis remain consistent over time [15]. 


\section{Mucosal abnormality of sinuses on CT Scan-} Mucosal abnormality percentage of various paranasal sinuses noted on CT scan in present study was compared with other studies. In the present study, maxillary sinus was most frequently involved in $80 \%$ cases followed by anterior ethmoid, posterior ethmoid, sphenoid \& frontal sinuses respectively. Similar observations were also made by Calhoun et al [16] and Stoney et al[17].

Patterns of Sinonasal Disease- In present study, five recognisable patterns of inflammatory sinonasal disease on CT was noted. 1st was infundibular pattern when obstruction occurred within the maxillary sinus, infundibulum resulting in blockage of ipsilateral OMC. 2nd was Osteomeatal unit pattern- when obstruction occurred within the middle meatus with resultant possible ipsilateral maxillary, anterior ethmoidal, middle ethmoid \& frontal sinusitis. 3rd was spheno ethmoidal recess pattern when Inflammatory post nasal pathology leads to obstruction of sinus ostia in spheno ethmoidal recess with variable involvement of ipsilateral posterior ethmoid and sphenoid sinuses. 4th was sinonasal polyposis pattern when characteristic findings included polypoid masses filling nasal vault and sinuses, bilateral infundibular enlargement, convex (bulging) ethmoid sinus walls, attenuation of bony nasal septum and ethmoid trabeculae. 5th was sporadic or unclassifiable pattern - when the inflammatory disease did not fit into the obstructed mucous drainage routes of pattern or polyposis pattern. Preoperative \& post operative sporadic inflammatory changes, retention cysts \& mucocele were included within this pattern.

In the present study OMU pattern was the most common pattern to be observed and was present in 35\% of cases, Infundibular in $20 \%$ of cases, Sporadic in $15 \%$ of cases, SER pattern was observed in $23.3 \%$ \& SNP in $6.6 \%$ of patients on $\mathrm{CT}$ scan. Our results are comparable to Asruddin et al [18].

\footnotetext{
Anatomic variations in region to paranasal sinuses noted on CT scan in present study- Anatomic variations are important for that they may narrow normal drainage channels, thereby predispose to chronic recurrent sinusitis. They increase operative risk and surgeon should be forewarned about these. Different investigators report different prevalence rates. Though variations may be encountered in the normal population (without sinusitis) their prevalence rates are significantly higher in patients with chronic sinusitis. In our study we observed that DNS, Concha Bullosa,
}

Haller cells, Onodi cells \& Pneumatization of pterygoid process were the common anatomic variants in $46.6 \%$, $33.3 \%, 25 \%, 28.3 \%, 13.3 \%$ of patients. Where as Agger nasi cells, pneumatization of anterior clinoid process, enlarged bulla ethmoidalis, pneumatization of crista galli, paradoxical middle turbinate were noted in $16.6 \%$, $6.6 \%, 10 \%, 8.3 \%, 8.3 \%$ of patients respectively.

Association of DNS with ipsilateral maxillary sinus disease- In our study out of 28 patients having DNS, maxillary sinus disease was present in 16 patients on one side but also present at the same time on contralateral side in 12 patients, so incidence of sinusitis in maxillary sinuses ipsilateral and contralateral to the side of nasal septal deviation was almost equal. The same was also observed with anterior ethmoid sinus disease. The results are comparable to Yousem et al[19]. So, it is concluded that septal deviation affected both ipsilateral and contralateral sinuses equally and there is no significant association of deviation of nasal septal disease with ipsilateral maxillary and/or anterior ethmoid sinus disease and this reflected multi factorial components involved in causation of sinusitis.

Agger NASI cells- Agger nasi cells were observed in $16.6 \%$ of cases in our study. Incidence was noted to be $15 \%$ by Stoney et al[17] and $48 \%$ by Asruddin et al[18]. So our incidence is almost comparable to other studies.

Haller Cells-Haller cells were observed in $25 \%$ of cases in our study. Prevalence of Haller cells have been reported to be $10 \%$ Zinreich [20] to $45 \%$ of cases Bolger et al,[21]. Asruddin et al[18] observed haller cells in $28 \%$ cases.

In our study along with 9 Haller cells on left ipsilateral maxillary sinus disease was seen in 5 sinuses and absent in other 4 , while on right along with 8 Haller cells, ipsilateral maxillary sinus disease was seen in 4 and absent in 4 sinuses. So, no significant association was found between Haller cells and ipsilateral maxillary sinus disease. This was also observed by Bolger et $\operatorname{al}[21]$.

Concha Bullosa- In the present study concha bullosa was seen in $33.3 \%$ of patients. Incidence of concha bullosa was noted to be $34 \%$ by Zinreich et al[22], 33$36 \%$ by Shroff et al[23], $10 \%$ by Lusk et al[24] and $28 \%$ by Asruddin et al[18]. Though there may be difference of incidence in different studies, size of the anatomic variant and its relationship with surrounding structures is much more important than presence only of 
the anatomic variant. However in our study, no significant association was observed between concha bullosa and ipsilateral OMU disease. Our results match with those of Zinreich et al[22] in that overall incidence or inflammatory disease in the osteomeatal complex in symptomatic patients was not different between those with and without concha bullosa.

Paradoxical Middle Turbinate- Incidence of paradoxical middle turbinate in our study was observed to be $8.3 \%$. Incidence of paradoxical middle turbinate was $<10 \%$ according to Yousem et al[19], $15 \%$ according to Zinrech[20] and $12 \%$ according to Asruddin et al[18].

Pneumatization of crista galli, anterior clinoid process \& pneumatization of pterygoid process- In present study pneumatization of crista galli was seen in $8.3 \%$ cases and anterior clinoid process in $6.6 \%$ cases, pterygoid process pneumatization was seen in $13.3 \%$. According to Bolger et al[21] any degree of pneumatization of the anterior clinoid process was considered significant and noted incidence of crista galli pneumatization in $83.7 \%$ cases of anterior clinoid process pneumatization in $13.3 \%$ and of pterygoid process in $43.6 \%$ of cases.

Infundibular opacification and ipsilateral maxillary sinus disease- In present study when infundibulum was opacified $94.4 \%$ of ipsilateral maxillary sinuses showed mucosal abnormality on CT scan. when infundibulum was normal, only $4.1 \%$ of the ipsilateral maxillary sinuses were abnormal.

So, there was significant association between infundibular opacification and ipsilateral maxillary sinus disease. Our results are comparable to Bolger et al[21], who found that when disease was present in infundibulum, $98 \%$ of cases had mucosal thickening of ipsilateral maxillary sinuses. When infundibulum was normal, ipsilateral maxillary sinuses were normal in $95.8 \%$ of cases.

CT and Endoscopy-Though CT is the most sensitive and specific currently available radiographic modality for diagnosis of chronic sinusitis. Moreover the findings during FESS reflect the exact pathology and remain superior to the evidence provided by CT. The endoscopy provides morphologic, histological and bacteriological information about state of nasal cavities and particularly middle meatus but endoscopy has got certain limitations like its inability to show frontal sinus and frontal recess, posterior ethmoid and sphenoid sinuses. CT is therefore a complementary procedures that ensures complete evaluation of AIM changes caused by inflammatory paranasal sinus disease.

In our present study we found that CT is highly sensitive and specific but FESS remains superior to CT because it reflects exact pathology of the paranasal sinuses.

Our results are comparable to Lazar et al[25] who stated that the high resolution $\mathrm{CT}$ of the sinuses is the most sensitive and specific radiographic modality. Despite good results, the CT scan is not an ideal radiographic modality. The findings during FESS reflect the exact pathology and remain superior to the evidence provided by CT. We do agree with Terrier et al[26] that endoscopy provides morphologic, histologic and bacterologic information about state of nasal cavities and middle meatus.

CT may reveal an anatomic abnormality that predisposes sinusitis. However, the treatment (medical or surgical) should be based on combined information extracted from clinical evaluation, CT and endoscopy findings. When considering the overall success rates in the postoperative period, the results of FESS are very satisfactory. An improvement rate of $80 \%$ to $98 \%$ in this sense is found for FESS in the literature. The authors attribute this small percentage of failure to different factors in the pathophysiology of the disease, including environmental factors like pollution, dust and cigarette smoke [27]. In the study by Damm et al [28] the overall improvement after surgery was $85 \%$, while Bhattcharyya et al [29] described improvement in $100 \%$ of patients, especially in the following symptoms: facial pain, congestion, nasal obstruction, rhinorrhea, and headache.

\section{Conclusion}

CT scan detected more sinonasal inflammatory disease than endoscopy but endoscopy helped in further characterization of contents of opacified sinus on $\mathrm{CT}$ scan. CT is the imaging modality of choice to reveal mucosal changes deeper in osteomeatal complex which are not visible endscopically and to identify extent of paranasal sinus disease. Direct visualization using endoscopy allows surgeon to assess the exact nature of disease during surgery. Endoscopy is specially useful in delineating type of soft tissue; causing opacification on CT scan whether it is due to polyp, hypertrophied 
mucosa or discharge. Endoscopy only displays the surface mucosa of ethmoid cells while CT shows it in depth displaying air chambers that are hidden from telescope. So, changes identified by CT should be correlated with symptoms and endoscopy findings.

Funding: Nil, Conflict of interest: None initiated, Permission from IRB: Yes

\section{References}

1. Lanza DC, Kennedy DW. Adult rhinusitis defined. Otolaryngol Head Neck Surg 1997;117 (3 Pt2):S1-7.

2. Lund VJ, Kennedy DW, and the Staging and Therapy Group. Quantification for staging sinusitis. Ann Otol Rhinol Laryngol 1995;167(Suppl):17-21.

3. Shapiro ED, Milmoe GJ, Wald ER, Rodnan JB, Bowen AD. Bacteriology of the maxillary sinuses in patients with cystic fibrosis. J Infect Dis. 1982 Nov;146(5):589-93.

4. Yousem DM. Imaging of sinonasal inflammatory disease. Radiology 1993;188:303-14.

5. Davidson TM, Brahme FJ, Gallagher ME. Radiographic evaluation of nasal dysfunction: computed tomography versus plain films. Head Neck 1989;11:405-9.

6. Kronemer KA, McAlister WH. Sinusitis and its imaging in the pediatric population. Pediatr Radiol. 1997 Nov;27(11):837-46.

7. Duvoisin B, Landry M, Chapuis L, Krayenbuhl M, Schnyder P. Low-dose CT and inflammatory disease of the paranasal sinuses. Neuroradiology. 1991;33(5):4036.

8. Rao VM, el-Noueam KI. Sinonasal imaging: anatomy and pathology. Radiol Clin North Am. 1998 Sep;36(5):921-39, vi.

9. Tack D, Widelec J, De Maertelaer V, Bailly JM, Delcour C, Gevenois PA. Comparison between lowdose and standard-dose multidetector CT in patients with suspected chronic sinusitis. AJR Am J Roentgenol. 2003 Oct;181(4):939-44.

10. Gotwald TF, Zinreich SJ, Corl F, Fishman EK. Three-dimensional volumetric display of the nasal ostiomeatal channels and paranasal sinuses. AJR 2001;176:241 -45.
11. Stammberger H. Endoscopic endonasal surgeryconcepts in treatment of recurring rhinosinusitis. Part 1. Anatomic and pathophysiologic considerations. Otolaryngol Head Neck Surg 1986;94:143.

12. Shazo RD, Chapin K, Swain RE. Fungal sinusitis. N Engl J Med. 1997 Jul 24;337(4):254-9.

13. Yousem DM. Imaging of sinonasal inflammatory disease. Radiology. 1993 Aug;188(2):303-14.

14. Elahi M, Frenkeil S, Remy H et al. Development of a standardized proforma for reporting computerized tomographic images of the paranasal sinuses. The Journal of Otolarygology 1996;25(2):113-20.

15. Bhattacharyya $\mathrm{N}$. Test retest reliability of computed tomography in the assessment of chronic rhinosinusitis. Laryngoscope. 1999 Jul;109(7 Pt 1):1055-8.

16. Calhoun KH, Waggenspack GA, Simpson B et al. $\mathrm{CT}$ evaluation of the parnasal sinuses in symptomatic and asymptomatic populations. Otolaryngol Head Neck Surg. 1991 Apr;104(4):480-3.

17. Stoney p, Probst L, Shankar L et al. CT scanning for functional endoscopic sinus surgery: analysis of 200 cases with reporting scheme. J Otolaryngol. 1993 Apr;22(2):72-8.

18. Asruddin, Yadav SPS, Yadav RK et al.Low dose CT in chronic sinusitis. Indian J Otolaryngol Head Neck Surg. 1999 Dec;52(1):17-22. doi: 10.1007/BF02996425.

19. Yousem DM. Imaging of sinonasal inflammatory disease. Radiology. 1993 Aug;188(2):303-14.

20. Zinreich J. Imaging of inflammatory sinus disease. Otolaryngol Clin North Am. 1993 Aug;26(4):535-47.

21. Bolger WE, Butzin CA, Parsons DS. Paranasal sinus sinus bony anatomic variations and mucosal abnormalities:CT analysis for endoscopic sinus surgery. Laryngoscope. 1991 Jan;101(1 Pt 1):56-64.

22. Zinreich SJ, Mattox DE, Kennedy DW et al. Concha Bullosa: CT evaluation. J Comput Assist Tomogr. 1988 Sep-Oct;12(5):778-84.

23. Shroff MM, Kirtane MV, Shukla A et al. Anatomic variants and mucosal abnormalities in paranasal sinus 
CT -A study in patients with chronic sinusitis. Ind $\mathrm{J}$ Radiol Imag 1991;Nov:51-6.

24. Lusk RP, McAlister B,el-Fouley A. Anatomic variation in pediatric chronic sinusitis- A CT study. Otolaryngol Clin North Am. 1996 Feb;29(1):75-91.

25. Lazar RH, Younis RT, Parvey LS. Comparison of plain radiographs, coronal $\mathrm{CT}$ and intraoperative findings in children with chronic sinusitis. Otolaryngol Head Neck Surg. 1992 Jul;107(1):29-34.

26. Terrier F, Webei W, Ruefenacht D et al. Anatomy of ethmoid: CT, endoscopic and macroscopic . AJR Am J Roentgenol. 1985 Mar;144(3):493-500.
27. Danielsen A, Olofsson J. Endoscopic sinus surgery. A long-term follow-up study. Acta Otolaryngol. 1996 Jul;116(4):611-9.

28. Damm M, Quante $G$ et al. Impact of functional Endoscopy Sinus Surgery on Symptoms and Quality of Life in Chronic Rhinosinusitis. Laryngoscope. 2002 Feb;112(2):310-5.

29. Bhattacharyya N. Symptom Outcomes After Endoscopic Sinus Surgery for Chronic Rhinosinusitis. Arch Otolaryngol Head Neck Surg. 2004 Mar;130(3):329-33.

\section{How to cite this article?}

Kumari A, Kaur A, Mathur M, Singh J., Mohi J.K., Haq S. Comparison between preoperative computed tomography scan of paranasal sinuses and operative findings in functional endoscopic sinus surgery (FESS) in chronic sinusitis . Int $J$ Med Res Rev 2016;4(12):2147-2155.doi:10.17511 /ijmrr. 2016.i12.12. 